\title{
Delegating Diplomacy: Rhetoric Across Agents in the United Nations General Assembly
}

\author{
Alexander Baturo \\ School of Law and Government \\ Dublin City University \\ Glasnevin, Dublin 9, Ireland \\ alex.baturo@dcu.ie
}

\author{
Julia Gray \\ Political Science Department \\ University of Pennsylvania \\ jcgray@sas.upenn.edu
}

\begin{abstract}
When political principals send agents to international organizations (IOs), those agents are often assumed to speak in a single voice. Yet various types of country representatives appear on the international stage including permanent representatives as well as more overtly "political" government officials. We argue that permanent delegates at the United Nations face career incentives that align them with the bureaucracy, setting them apart from political delegates. To that end, they tend to speak more homogeneously than do other types of speakers, while also using relatively more technical, diplomatic rhetoric; and career incentives will make them more reluctant to criticize the UN. In other words, permanent representatives speak more like bureaucratic agents than like political principals. We apply text analytics to study differences across agents' rhetoric at the UN General Assembly. We demonstrate marked distinctions between the speech of different types of agents, contradictory to conventional assumptions, with implications for our understandings of the interplay between public administration and agency at IOs.
\end{abstract}

Key Words: United Nations; diplomacy; leaders; diplomatic speech 
States choose to delegate more than just authority to international organizations (IOs) (Abbott et al., 2016). They also confront a choice of whom to delegate to deliberative bodies within those IOs. As more and more IOs add parliaments and representative bodies to their structures (Lenz et al., 2019), this choice of delegation becomes increasingly relevant to international governing structures as well as to their member states (Pollack, 1996). Yet little is known about how different types of delegates conduct business in the world's most inclusive and longestenduring deliberative body, the United Nations General Assembly (UNGA).

Part of the reason that the choice of delegation remains understudied is that core theories of international relations (IR) glossed over the idea that different agents could differently represent the same principals. Countries' behavior in international organizations was understood to be the product of "state interests," assumed to be consistent regardless of whom was representing that state. ${ }^{1}$

And yet, the public-administration perspective differs. Permanent representatives - usually hailing from an international class of diplomats - were meant to boast not only the technical expertise but also the political neutrality necessary to ensure the UNGA's legitimate and effective deliberations (Pouliot, 2015). Even though permanent representatives still have the primary task of communicating their home country's preferences, they may prefer to remain in control of their own domains (Barnett and Finnemore, 1999; Hawkins et al., 2006) and to have careers that are aligned more internationally than domestically (Johnson, 2014).

We argue that unlike political actors, permanent delegates conduct themselves in the same manner as do bureaucrats more generally. Permanent representatives constitute a professional class of experts in diplomacy — a reality that was built in to early theories of international cooperation as well as to the design of the UNGA (Webster, 1947). As such, permanent delegates share certain characteristics among their group, which we show using a variety of text analysis tools. They speak more homogenously as a group, reflecting their socialization as a class 
(Finnemore, 1996). Furthermore, their language is more 'diplomatic' than that of their political counterparts, as well as more sophisticated in terms of comprehension and readability, and is also more specific. Consistent with incentives to preserve their international careers rather than to serve domestic constituencies, they are also more likely to speak positively about the UN itself. To that end, their speech is likely directed to international, rather than domestic audiences. In contrast, delegates who are closer to national politics tend to speak more heterogenously, (reflecting their various countries' national interests across countries), and more simply, as reflected in more political speech. This demonstrates that permanent representatives - mindful of their own international careers and socialized as a diplomatic class — have incentives to act in a manner distinct from more politicized delegates.

We present evidence using new data on speech at the UNGA (Baturo et al., 2017). At the UN's signature deliberative forum, many types of delegates - including permanent delegates as well as more overtly politicized actors, such as heads of state or ministers of foreign affairs — express their country position. This affords a rare opportunity to compare rhetoric across actors, holding the forum constant. Thus, this empirical arena stands in contrast to other rhetorical examinations of bureaucratic actors within their own domain, such as in reports (Patz and Thorvaldsdottir, 2021; Patz et al., 2020), where only a single actor's speech is examined over time.

We contribute to research that shows how the routine details of diplomatic interactions can shape cooperation or conflict (Adler and Pouliot, 2011; Bueger and Gadinger, 2015). These studies highlight the role of diplomats in bilateral relations (Neumann, 2012; Lebovic and Saunders, 2016) as well as the role of differing levels of delegation in IO staff can impact cooperative outcomes (Hawkins et al., 2006; Vaubel et al., 2007; Parizek, 2017). In these accounts, individual diplomats can have discrete influence on policy outcomes (Gertz, 2018; Lindsey, 2017; Jordan and Tuman, 2018), and professional diplomatic technocrats face differ- 
ing incentives than do political actors (Johnson, 2013; Skovgaard Poulsen and Aisbett, 2016). Such lenses have already been applied to the UN, showing how, for example, changes in the appointment process of the Secretary General have influenced policy outcomes (Wiseman, 2015). These approaches have also acknowledged, and analyzed, the particular importance of speech in diplomacy (Jönsson and Hall, 2003; Bayram and Ta, 2019).

Understanding the variation in rhetoric across delegates in the UNGA shed important light on the way that the UN bureaucracy works, while also casting a broader lens on the relationship between politics and bureaucracies (Aberbach et al., 1981; Peters, 1978). Studies of delegation to IOs have tended to focus primarily on the delegation inherent in the act of membership (Abbott and Snidal, 1998; Tallberg, 2002), or the delegation of competencies to agencies within IOs (Pollack, 1996; Alter, 2008). Some scholars do examine the dynamics of particular delegates in IOs. ${ }^{2}$ Yet few recent papers have examined quantitatively different delegates at the UN. ${ }^{3}$ This is surprising, as much of the early empirical work on the UN centered on the way in which individual delegates, and their qualifications, influenced the cooperative process within the UN (Jacobson, 1967), and particularly the UNGA (Keohane, 1969).

This paper also contributes to the literature on international public administration (IPA) (e.g., Barnett and Finnemore, 2004, 1999; Bauer et al., 2017; Busch et al., 2021; Eckhard and Steinebach, 2021; Eckhard and Jorn, 2016; Wagner et al., 2021) by expanding the definition of what typically constitutes an international bureaucracy. Although permanent delegates are technically closer to principals than to agents, their speech is more closely aligned to bureaucrats. We shed light on an underexplored tension that undercuts delegates who are also part of, and have allegiances to, international administrations. 


\section{Permanent Delegation at the UNGA}

Much IR theory assumes that state preferences explain most outcomes in IOs. And yet early conceptions of international governance stressed differences across different agents from the same state. At the beginning of the 20th century, policymakers and public intellectuals argued over the most effective form of international governance, one that harnessed diplomatic expertise and norms while remaining grounded in domestic politics. At the time, representation was among the more important institutional design features of international cooperation. Once ideas of international governance had moved away from exclusively legal conceptions, such as the Hague conferences of 1899 and 1907, the dominant post-World War I view was to have the League of Nations embody an international civil service removed from politics (RanshofenWertheimer, 1945). This reflected a consensus that national interests should take a back seat to the complexities of international governance, and that international cooperation was best stewarded by diplomatic experts rather than by politicians (Kindleberger, 1955; Wertheim, 2012). Although the design of the League of Nations did include an assembly for parliamentarians, it was intended to only meet every few years, with the majority of the work taking place in the Council.

Permanent representatives were meant to counsel the League on their country's position, but as one scholar put it, "The tendering of advice to League authorities easily becomes an effort to promote the national interest. ... This activity is not, on the other hand, carried on by the permanent delegate nearly as vigorously as might be expected, and it is balanced by the service which he also renders of contributing his government's share in the support and promotion of the work of the League" (Potter, 1931, 43). Even in the early days of IPA, "the creation of the permanent delegations tends to develop ... a professional diplomatic clique and an atmosphere of professional diplomacy" (Potter, 1931, 47). Thus, anecdotal evidence suggests than in the League, permanent representatives were closer to the IPA conception of an "international man" 
who was beholden to no national bias and therefore more capable of finding objective solutions to problems of international cooperation (Ranshofen-Wertheimer, 1945).

World War II upended the League's model of cooperation conducted primarily by neutral agents - and the subsequent design of the UN reflected this shift. In the initial proposals for the UN, the United States, the Soviet Union, and the United Kingdom all favored "a Council composed of Great Powers and some smaller states," with the understanding that "the responsibility for the maintenance of international peace and security should be placed on the Council," and that the "powers for this ... should not be shared with the Assembly" (Webster, 1947, 2627). Instead, the UNGA was meant to serve as a forum for both inclusion as well as discussion, intended to represent the "deliberations of diplomats gathered in public assembly [to] develop a new kind of esprit de corps based upon more than professional solidarity. The habit of working together on an organized and thorough footing would equip diplomats to tackle issues before they became dangerous and threatened war. ... Diplomats would enter the assembly ignorant of everything but the arguments of raison d'etat to graduate as citizens of one world, reasonable men embodying "the reason of the whole"' (Keens-Soper, 1984, 78-79).

To that end, permanent delegates to the UNGA were meant to act and debate as the types of bureaucratic experts that dominate models of IPA. And yet, many dominant theories of IR assume a homogeneity of behavior across delegates from the same state principal. On the one hand, many of the core theories of international collaboration center on the idea that actors in international fora can become socialized into norms of cooperative behavior (Finnemore and Sikkink, 2001; Johnston, 2001; Bearce and Bondanella, 2007). On the other hand, principalagent theories tell us that there can be a degree of slack when certain competencies are handed off to third parties (Hawkins et al., 2006; Johnson, 2014). These ideas are to some extent in contradiction with one another: while agents may be better stewards of complicated or sensitive matters of international governance, when left to their own devices, they may direct policy in a 
direction more attuned to their own interests than to that of the principals (in this case, national governments).

\section{Hypotheses: Political vs Diplomatic Agents in Deliberation}

Contrary to the assumption that delegates represent unified "state interests," we argue that diplomatic agents speak differently than political agents. Permanent representatives have several attributes that set them apart from political principals. The first is diplomatic expertise. From the origins of the UN, permanent representatives were meant to act as "a body of experts" who could offer governments counsel on the appropriateness of using the UN for a foreign policy aim; how to raise a given issue; and how to maximize gains from UN participation (Pedersen, 1961). Many early scholars focused on the crucial expertise of permanent representatives; as one scholar put it, "In the setting of international conferences, the representative must practice the arts of both the negotiator and parliamentarian" (Thompson, 1965, 396).

Diplomatic skill as well as procedural savvy are valued in these delegates, and permanent representatives forged relationships within the UN based on their own reputations for competence (Alter, 2008; Pouliot, 2016). These reputations often lead to careers that tile more toward the international realm than the domestic one (Johnson, 2014; Lindsey, 2017), as befits "“denationalised cosmopolites and globetrotters" (Ranshofen-Wertheimer, 1945, 646). As such, their professional incentives tend to be structured more toward employment in other IOs than in their own domestic governments. That would indicate that the audiences for their speech were not the domestic publics of their home country, and perhaps - to whatever extent defensible — not even explicitly their home governments, although they must certainly still represent their government positions. Rather, the audience for their speeches might more likely be the international class of diplomats and IOs.

Furthermore, unlike more political delegates who tend to be embedded in national govern- 
ments, permanent representatives are based in New York at the UN itself. By virtue of their taking part in "clan politics" as well as the constant socialization of being on site (Pouliot, 2016), they may also become more socialized not only in the norms and practices of the organization (Finnemore, 1996) but also in one another's stances on international issues. This means that, despite their widely varying country positions, permanent delegates as a class may function more homogenously than do more political delegates. In other words, permanent delegates the world over assume "a rather peculiar diplomacy of groups" (Pouliot, 2015, 95), indicating that their behavior should be more unified, when compared with that of other types of delegates.

These qualities should be reflected in agents' speech (Bayram and Ta, 2019). Rhetoric is an important part of delegates' conduct, as has been shown in the study of courts (Alter, 2008), central banks (Baerg, 2020), domestic and international parliaments (Proksch and Slapin, 2012), as well as dictatorships (Baturo and Mikhaylov, 2013). In international parliaments, the speeches of delegates are often more visible than the votes that they cast, as has been shown in an EU context (Magnette and Nicolaidis, 2004).

These theories point to several testable hypotheses. The first centers on speech sophistication with respect to complexity, specificity, and diplomatic jargon. Because permanent delegates have internationally oriented career incentives, their rhetoric will be more likely to target their diplomatic peers. As Lindsey (2017) posits, permanent representatives are more closely aligned with their host's preferences. This should translate to speech that is more lexically complex, as befits the language of educated international diplomats.

Furthermore, rather than relying on the generalized and often-abstracted language of politics, permanent representatives should be incentivized to speak more specifically, invoking particular named entities. In other words, permanent representatives' speech will be more focused on specific issues. Rather than attempting to project power and convey broad ambition (Smith, 1996), as political actors might, permanent delegates tend to focus on more specific 
matters, the everyday diplomacy of the UN, and their national foreign policy priorities and goals.

Along those same lines, permanent representatives will likely use more technical language. If they are more aligned with the international class than with the voting publics of their home country, their rhetoric need not be simplified and direct, in the manner of political speeches. They should more readily deploy the lexicon of diplomacy than would political delegates, as permanent representatives tend to be well-versed in diplomatic jargon and rely on it in their communications. As Pedersen $(1961,262)$ put it, "professional people concerned with preparing speeches and determining policies in the United Nations, both in foreign offices and in delegations, are likely to oppose speaking methods attractive to a general audience and to support those more suitable for the committee."

Sophistication, of course, can be either a liability or an asset, and we do not examine the consequences of this type of speech either for advancing a country's interest in the UNGA or for the effectiveness of debate. Permanent representatives have their own incentives to adhere to this type of rhetoric, and as in all types of bureaucratic communication, it can simultaneously lend itself to obfuscation (Dewan and Myatt, 2008), while still compatible with a bureaucrat's purpose. To that end, higher values of sophistication in speech should neither be seen as a merit nor a disadvantage; rather, we seek to argue simply that permanent representatives as a class will tend to deploy this type of rhetoric.

This leads to our first hypothesis on speech sophistication for permanent delegates compared with political actors. All of our hypotheses center on differences between permanent representatives and other types of delegates.

- $\mathbf{H}_{1}$ : Speech Sophistication in Permanent Representatives: The speech of permanent representatives will be more specific, more complex, and more reliant on diplomatic jargon, than will that of political actors. 
Furthermore, permanent delegates occupy a more rarefied space than do political delegates. Permanent representatives who live and work more or less on site, as noted by Pouliot (2016, 121), are, in the words of one delegate, "all the time together. We have our bank, our restaurant, our cafe, post office and hairdresser and so it's this microcosm where, of course, you use your time outside the meetings to network and have contacts with colleagues." The bubble in which permanent delegates operate, as a function of spending social as well as professional time together, will lead to greater socialization within that group than one would expect to see from political delegates, who often fly to New York for only a few days surrounding the UNGA sessions. To that end, we would expect less variation within permanent delegates' speech, compared with greater divergence within the speeches of MFAs or political leaders. Those political delegates have their own constituencies' varying issues to address, whereas permanent delegates will be socialized to speak more similarly, due to their bureaucratic isolation.

- $\mathbf{H}_{2}$ : Speech Homogeneity in Permanent Representatives: Permanent delegates' speech will have greater similarity across delegates than will the speeches of political actors.

Finally, much work has focused on the career incentives of bureaucrats, as they differ from political actors (Schneider, 1993; Carpenter, 2001; Alesina and Tabellini, 2007). Heads of state are accountable to the electorate and tailor their appearances accordingly; ministers of foreign affairs also tend to have political careers. By contrast, permanent representatives usually operate exclusively in the world of diplomacy, and many have long careers at the UN. To that end, they have little motivation to criticize their employers (Lindsey, 2017), compared with political actors who may score points with domestic audiences by voicing negativity toward the UN. This suggests differences across agents with speech sentiment, as follows:

- $\mathbf{H}_{3}$ : Speech Sentiment in Permanent Representatives: Permanent delegates' speech will be less negative toward the UN than will the speeches of political actors. 


\section{Examining Differences in Rhetoric Across Delegates}

We test our argument using two types of data related to the UNGA. We combine original data on attendees (described in the appendix) with the text corpus of UN speeches from Baturo et al. (2017). Speeches made during the UN debate typically cover the most salient issues in global politics and national foreign policy priorities in a given year. On average, speeches include 114 sentences, 3,057 tokens (words), and 964 types (unique forms of words). From almost 10,000 attendees from 1946-2019, 1,248 (13 percent) are permanent delegates. On face value, permanent and political delegates do not differ in terms of the length of their speeches. Thus, diplomats deliver their statements using 100 sentences and 3,015 tokens on average, versus 114 sentences and 3,061 tokens by other types of speakers.

\section{Tests of Hypothesis 1: Speech Sophistication Within Agents}

Our hypotheses question the assumption that agents all represent the same principal and are therefore indistinguishable in their speech. To explore differences in speech between permanent and political delegates, we fit a series of regression models with random effects and time-period controls. Each model has a different dependent interval variable that measures various aspects of speech in the United Nations. The main explanatory variable is a binary measure taking the value of one when the speaker is a permanent delegate, with the value of zero for political delegates, in a given country-year. The data cover all UNGA sessions from 1970 to 2019. For robustness, we additionally include dummy variables for the four major regional caucusing blocks (Peterson, 2006, 45-47).

First we examine the difference in terms of speech complexity between permanent and political delegates. The first component of these tests is specificity. We hypothesise that delegates closer to national political interests — such as ministers of foreign affairs or heads of state may be more likely to obfuscate and talk about foreign policy issues in generalist language, 
centred on lofty goals and challenges facing humankind. Less specific language can provide these speakers with greater political cover. In contrast, permanent delegates have more latitude to specifically refer to particular individuals, entities and places, whether criticising or praising their partners or rivals. We therefore extract personal and location names using a named-entity recognition (NER) process, which tokenizes all words in a text, classifies them and then identifies named entities into categories - including, for example, places, locations, and organizations. We then estimate the percentage of such names to all terms in each text. Higher values indicate a greater degree of specificity in a given UN address. ${ }^{4}$

Table 1 displays the results of the analyses. In the first two columns we place the results of the analyses that compare speech specificity (persons in Column 1 and locations and organizations in the second column) of permanent and political representatives. As can be seen from Columns 1-2, diplomats tend to use more specific language, and the differences are statistically significant. This offers support for Hypothesis 1a.

Differences in speech also emerge when looking at lexical complexity. To show that permanent representatives use more sophisticated expression, we implement two tests. First, we use the Flesch-Kincaid readability test that is designed to measure how difficult a particular text in English is to understand (Flesch, 1948). The score roughly corresponds to with a U.S. school grade level, where a higher score indicates text that is more complex and difficult to read. On average, UN texts score over 15 on the Flesch-Kincaid test, which indicates that these texts are rather difficult to read and correspond to a college graduate level. Even though the texts delivered by permanent representatives are not dramatically different from those made by politicians, the differences are nonetheless statistically significant at 0.01 level, while controlling for covariates and time period effects (Column 3). This indicates that while all UN texts are rather complex, texts made by permanent representatives have a higher complexity. Because these speeches are meant to listen to and not only to read, we further implement an additional 


\begin{tabular}{|c|c|c|c|c|c|c|}
\hline & \multicolumn{2}{|c|}{ Specificity } & \multirow{3}{*}{$\begin{array}{c}\text { Readability } \\
\text { 3: }\end{array}$} & \multirow{3}{*}{$\begin{array}{c}\text { Listenabiility } \\
\text { 4: }\end{array}$} & \multirow{3}{*}{$\begin{array}{c}\text { Diplomatic } \\
5:\end{array}$} & \multirow{3}{*}{$\begin{array}{c}\text { Sentiment } \\
\text { about UN } \\
6:\end{array}$} \\
\hline & Person & Geo or org & & & & \\
\hline & 1: & 2: & & & & \\
\hline \multirow[t]{2}{*}{$\overline{\text { Permanent delegate }}$} & $0.000 * * *$ & $0.001 * * *$ & $0.240 * * *$ & $0.221 * *$ & $0.129 * * *$ & $0.329 * *$ \\
\hline & $(0.000)$ & $(0.000)$ & $(0.072)$ & $(0.073)$ & $(0.021)$ & $(0.141)$ \\
\hline \multirow[t]{2}{*}{ West European and Others } & $-0.001 * * *$ & 0.000 & $-2.101 * * *$ & $-2.078 * * *$ & $-0.092 * *$ & $0.598 * *$ \\
\hline & $(0.000)$ & $(0.001)$ & $(0.284)$ & $(0.278)$ & $(0.044)$ & $(0.290)$ \\
\hline \multirow{2}{*}{ Asia and the Pacific } & $-0.000+$ & $0.002 * *$ & $-0.560 * *$ & $-0.455 * *$ & $0.064+$ & $1.018 * * *$ \\
\hline & $(0.000)$ & $(0.001)$ & $(0.233)$ & $(0.228)$ & $(0.037)$ & $(0.240)$ \\
\hline \multirow{2}{*}{ Eastern European Group } & $-0.001 * * *$ & $0.005 * * *$ & $-0.698 * *$ & $-0.822 * *$ & 0.035 & $1.712 * * *$ \\
\hline & $(0.000)$ & $(0.001)$ & $(0.330)$ & $(0.323)$ & $(0.053)$ & $(0.349)$ \\
\hline \multirow{2}{*}{ Latin American and Caribbean } & -0.000 & $-0.005 * * *$ & -0.281 & -0.317 & $-0.237 * * *$ & 0.254 \\
\hline & $(0.000)$ & $(0.001)$ & $(0.269)$ & $(0.263)$ & $(0.042)$ & $(0.274)$ \\
\hline \multirow{2}{*}{ Constant } & $0.002 * * *$ & $0.032 * * *$ & $15.554 * * *$ & $11.206 * * *$ & $0.880 * * *$ & $4.264 * * *$ \\
\hline & $(0.000)$ & $(0.001)$ & $(0.174)$ & $(0.171)$ & $(0.029)$ & $(0.194)$ \\
\hline Time period controls & yes & yes & yes & yes & yes & yes \\
\hline$\overline{\chi^{2}}$ & 150.20 & 409.50 & 1075.11 & 1069.85 & 300.28 & 134.22 \\
\hline$\sigma(u)$ & 0.001 & 0.004 & 1.177 & 1.150 & 0.171 & 1.102 \\
\hline$\sigma(e)$ & 0.001 & 0.008 & 1.781 & 1.795 & 0.512 & 3.487 \\
\hline$\rho$ & 0.233 & 0.208 & 0.304 & 0.291 & 0.101 & 0.091 \\
\hline $\mathrm{N}$ & 7242 & 7239 & 7254 & 7254 & 7254 & 7138 \\
\hline $\mathrm{N}$ countries & 189 & 189 & 189 & 189 & 189 & 189 \\
\hline
\end{tabular}

Table 1: Difference between permanent and political delegates Note: All models are estimated as random effects regression. The UN African group is the omitted category. The dependent variables in Models 1-2 are the percentage of terms that are personal names (1) or geographic names and the names of organisations (2) to total number of terms; Flesch-Kincaid readability score — in 3; Easy Listening Formula score — in 4; Diplomatic dictionary share to total number of tokens - in 5; The ratio of positive to negative terms in 10-word windows around the $\mathrm{UN}$ and related terms (6). Significant $+p<0.10$, ** $p<0.05$, *** $p<0.01$.

test for listenability, that of an Easy Listening Formula (Fang, 1966), calculated as the number of words with two syllables or more divided by the number of sentences. As evidenced from Column 4, diplomats are somewhat more 'difficult' to listen to, because of the complexity of their speech.

We can also turn to an even more direct test of speech complexity, the likelihood of using specific diplomatic terms, such as nota verbale or bona fide. We detail such terms in Table 2. We hypothesised that diplomats are likely to use more technical, diplomatic jargon than

\begin{tabular}{cccccc}
\hline \hline accord & agrement & aide memoire & alternat & attache & belligerency \\
resolution & demarche & protocol & casus belli & communique & conciliation \\
treaty & envoy & rapprochement & ceteris paribus & consulate general & dispatch \\
plenipotentiary & modus & nota verbale & de jure & entente & exequatur \\
compromise & modus vivendi & excellency & ex officio & ex gracia & extraterritoriality \\
ratification & pact & interim & force majeure & high commissioner & legation \\
convention & non grata & bona fide & pro tempore & precedence & rapporteur \\
\hline
\end{tabular}

Table 2: Diplomatic Dictionary. Note: Drawn from Berridge and James (2003) and glossary of diplomatic terms at http: //www. ediplomat.com/nd/glossary.htm, accessed 17 March 2020. 


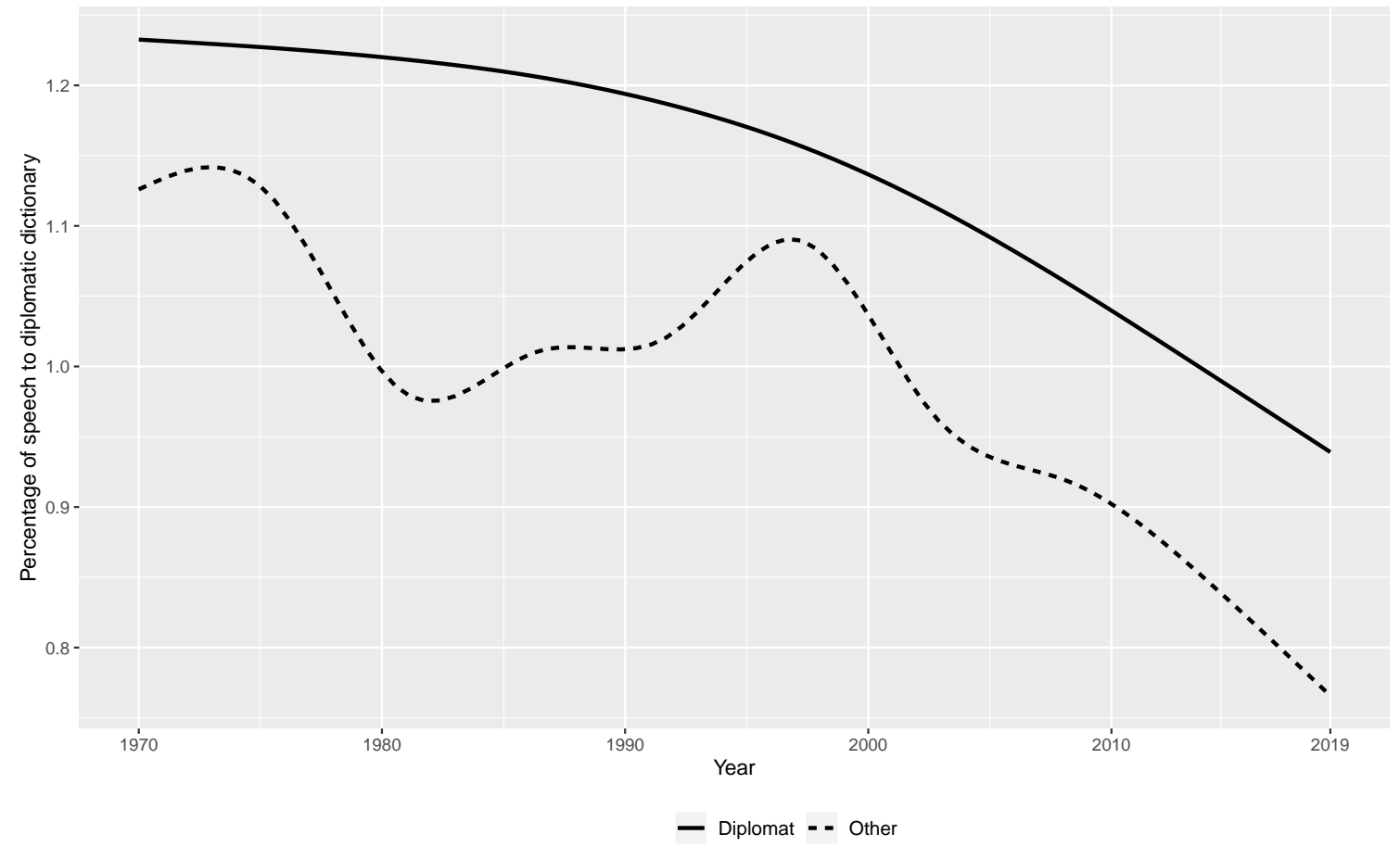

Figure 1: Diplomatic Rhetoric Over Time. Note: The share of Diplomatic Dictionary in speeches of permanent (diplomats) and political delegates (other) over time.

political delegates do. However, because many ministers of foreign affairs -a large group of speakers among political delegates — are senior professional diplomats as opposed to politicians, it is quite likely that permanent and political delegates alike will rely on diplomatic jargon in their addresses to the United Nations. As a test, we estimate the share of diplomatic dictionary - terms listed in Table 2 - in speech of UN delegates. Even though foreign ministers are more likely to rely on diplomatic jargon than political leaders —- on average 1.06 versus 0.79 - permanent representatives stand out even if we aggregate foreign ministers with other political delegates together: 1.15 versus 0.99 , and the difference is highly statistically significant, as evidenced by the results displayed in Column 5 of Table 1. In addition, Figure 1 further shows that even though the language that is prevalent in the UNGA has become less technical over time among both groups of speakers, permanent representatives continue to be more likely to use this dictionary, than other types of speakers.

Our second hypothesis stated that career incentives and professional socialisation make ca- 


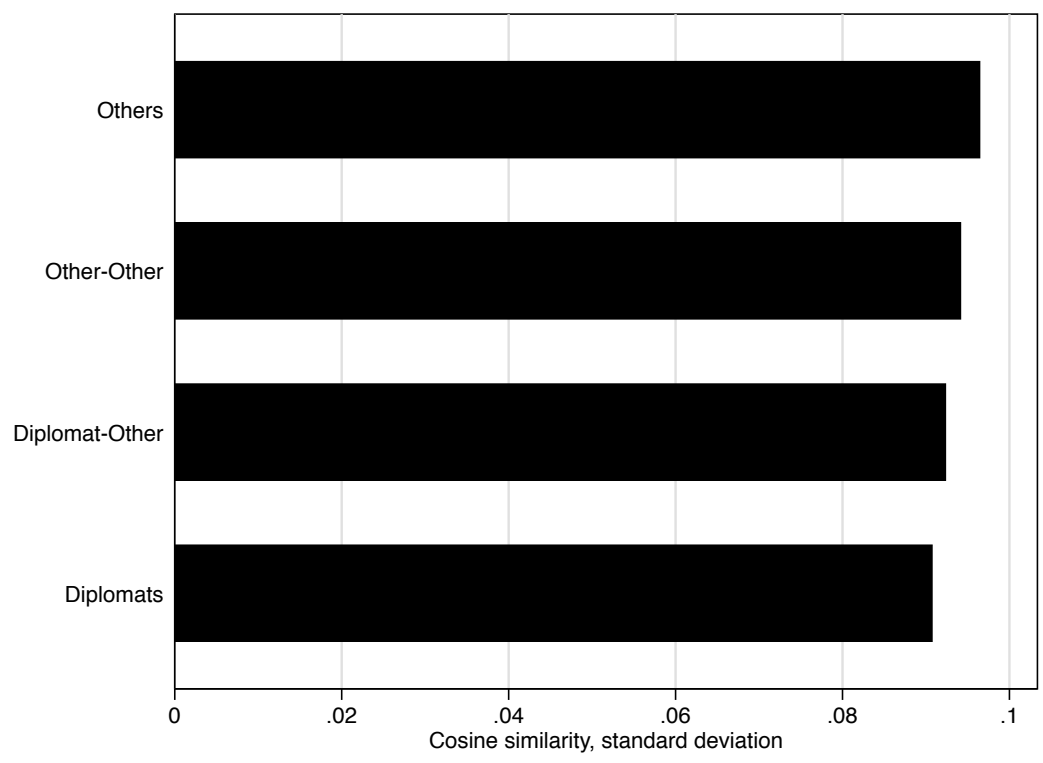

Figure 2: Cohesion of Speaker Groups. Note: Standard deviation of cosine similarity measure within different groups of speakers, as explained in text. Difference between the speeches of permanent representativesdiplomats (one group) and others (another group) is statistically significant (Student's t-value=10.753). Altogether, estimation sample includes 714,953 dyadic observations.

reer diplomats more positive about the UN, all things being equal $(\mathrm{H} 2)$. In the last model specification we therefore estimate the ratio of positive to negative terms in texts using the Lexicoder Sentiment Dictionary (Young and Soroka, 2012). Specifically, we count the negative-positive share of words in 10-word windows around the United Nations, international organisation, and international community (as bigrams). Results reported in Column 6 indicate that among all UN delegates, permanent representatives are the most positive about the international organisation.

Because our main focus is on permanent delegates, we relied on regional groupings as basic controls for UNGA politics. In the appendix we discuss them in more detail; we also include different variables, as well as alternative measures of UN voting blocks.

Finally, we examine evidence pointing toward higher cohesion among permanent delegates, in contrast to other groups of speakers (H3). Because permanent representatives spend more time at the institution and are socialized into the same technical class, we should expect the variance across their speeches to be smaller than in other types of delegate. As an empirical 
test, using the quanteda package (Benoit et al., 2013), we compute the cosine similaritystandard metric of textual similarity — between all documents in the text corpus. ${ }^{5}$ More similar documents that have similar counts of the same terms that occur in similar proportions will have higher cosines, that is, higher scores of similarity.

We estimate the cosine for every pair of texts, include the data on the profiles of speakers (whether they are permanent or political delegates), and then estimate the standard deviation of text similarity within each group of speakers. In other words, we examine similarities between speeches made by permanent delegates, between those made by permanent delegates and other speakers, as well as between non-permanent representatives of the same type, other (e.g., between political leaders and other political leaders), and of different type, other-other, e.g., MFAs and political leaders. These results are detailed in Figure 2. Because of a very large dyadic dataset, visually differences do not stand out dramatically. Still, permanent delegates as a group have the lowest average standard deviation among other groups, which indicates that professional diplomats tend to speak alike, certainly more alike that other groups of speakers. This offers support for the conjecture that permanent delegates tend to speak more homogenously.

These tests can be illustrated briefly by comparing speeches between a permanent representatives and a head of state in the case of Venezuela. Compare Jorge Valero, a career diplomat. Educated in London, he served as permanent delegate to not only the UN but also to the Organization of American States and on the governing board of OPEC Fund for International Development. At the same time, he was also loyal to the "Bolivarian revolution" cause of Venezuela's then-President Hugo Chávez. To that extent, his political predilections would suggest a more politicized type of speech, but his vocation would suggest a more diplomatic speech — and the latter evidences itself in his rhetoric. In Jorge Valero's UNGA address in 2010, in speaking about cooperation between developing nations, the following type of language is of- 


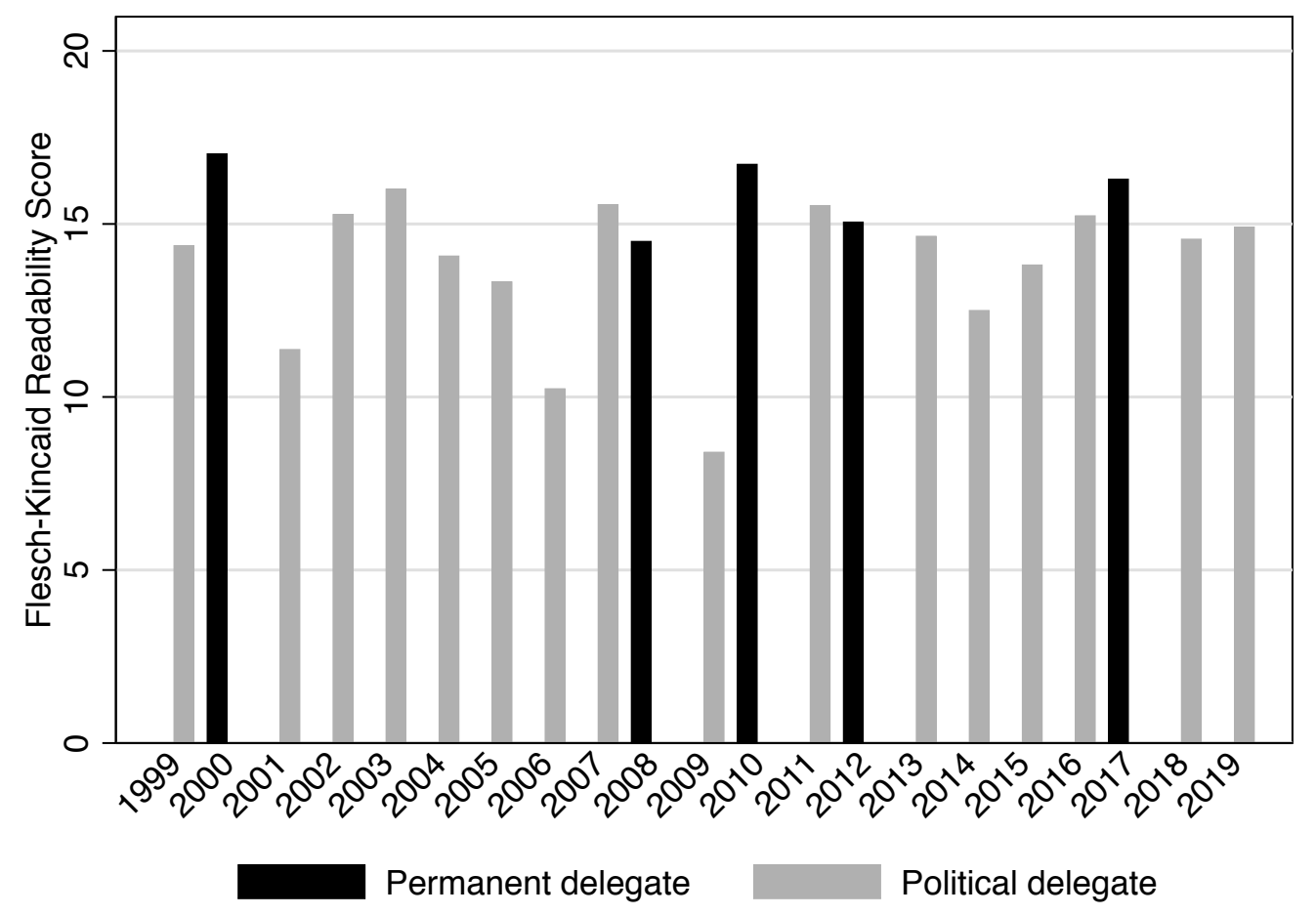

Figure 3: Text Readability of Venezuelan Representatives. Note: Based on Flesch-Kincaid Readability Score, higher values per speaker indicate higher complexity, differences between diplomats and other speakers are statistically significant (Student's $t$-value $=-2.180$ ).

ten encountered: "Faced with this crisis, developing countries should strengthen South-South cooperation and create alternative sovereign mechanisms to avoid the credit monopoly maintained by the Bretton Woods institutions.” For comparison, Chávez's 2009 speech on the same topic used less delicate language: "They attack us and try to stop us, but they will not succeed. The Common Market of the South and the Union of South American Nations are being set up and are all part of the great historic Latin American geographic and geopolitical revolution."

These differences play out in the metrics that we used throughout our analysis. In contrast to Jorge Valero's Flesch-Kincaid score of 16.724 , Chavez's speech is much more readable, at 8.404. It is also much more listenable, at a very low 4.748, in contrast to his diplomat's score of 11.842. Valero's diplomatic dictionary share is 2.12 , in contrast to Chávez's 0.244 , i.e., an almost zero usage of diplomatic terms. This example illustrates that even though permanent and political delegates convey the same message and foreign policy priorities as do politicians, they do it in a very different manner. 
Supplementary appendix includes models with additional predictors to explain differences in speech, as well as the results of the structural topic model, which suggests that permanent delegates are more likely to cover topics related to the UN affairs.

\section{Conclusion}

This paper has problematized the assumption that agents represent their principal in a unified voice. We show that permanent delegates' behavior is closer to that of international bureaucrats than to political actors. This also introduces an area of future research for the IPA literature. If even agents from the same principal face differing incentives and therefore communicate differently, this complicates our understanding of delegation in the international system. To that end, other types of delegates' behavior and incentives could be examined for similar patterns; for example, other types of delegates selected for expertise, such as environmental delegates (Kaya and Schofield, 2020), as well as leaders, political appointees, and ministers.

Differences in speech across different types of delegates suggest not only differing incentives but different audiences. Speeches are not only a method of expression; they also can target specific audiences as a method of persuasion, or expressions of solidarity, or even antagonism. Additionally, political delegates' simpler speech could be directed at their own domestic audiences. Further work could examine whom delegates hope to address when speaking at the UNGA.

Future work could also look at the effectiveness of various types of delegate in IOs. Much of the principal agent literature centers on the trade-off between agent's autonomy and principal's interests. Although insulation from political pressure can lead an agent to be more effective, this same mechanism can at the same time make agents less accountable and potentially less legitimate. Future work could examine the effectiveness of delegating diplomacy at the UNGA to permanent delegates rather than to political actors. Although heads of state may command 
more direct influence, the diplomatic process may be swayed by the persuasive tactics of agents trained in diplomacy, who build their reputations on personal relations and the ability to negotiate. ${ }^{6}$ As Jacobson (1967) put it, “the long-term impact of [permanent delegates'] personal contacts may be intangible, but it is nevertheless real."

Finally, states face choices of whom to delegate to international bodies, depending on what they hope to gain from those appearances. Although diplomats tend to speak in a more sophisticated and homogenous manner, there may be times when such speech serves a country's interest; on other occasions, rhetoric that is closer to a country's political interests may be more worthwhile. A full examination of delegation strategies to IOs is beyond the scope of this paper, but further research could examine the incentives that states face in terms of whether they send career bureaucrats or more political actors to speak in international fora. 


\section{Notes}

${ }^{1}$ See Finnemore (1996); Wendt (1987) for an opposing view.

${ }^{2}$ See Halliday et al. (2013); Pouliot (2015) for qualitative approaches.

${ }^{3}$ For an exception, see Parizek (2017).

${ }^{4}$ The Stanford Named Entity Recognizer (NER) software offers a general implementation of (arbitrary order) linear chain Conditional Random Field sequence models.

${ }^{5}$ It accounts for word counts occurring in different texts, and measures the cosine of the angle of these documents, when plotted on multiple dimensions with each dimension corresponding to each term.

${ }^{6}$ See Carpenter (2001) on reputation-building in US agencies. 


\section{References}

Abbott, K. and Snidal, D. (1998). Why states act through formal international organizations. Journal of Conflict Resolution, 47(1):3-32.

Abbott, K. W., Genschel, P., Snidal, D., and Zangl, B. (2016). Two logics of indirect governance: Delegation and orchestration. British Journal of Political Science, 46(4):719-729.

Aberbach, J. D., Putnam, R. D., and Rockman, B. A. (1981). Bureaucrats and politicians in Western democracies. Harvard Univ. Press, Cambridge, Mass.

Adler, E. and Pouliot, V. (2011). International practices. International Theory, 3(1):1-36.

Alesina, A. and Tabellini, G. (2007). Bureaucrats or politicians? part i: A single policy task. American Economic Review, 97(1):169-179.

Alter, K. J. (2008). Agents or trustees? international courts in their political context. European Journal of International Relations, 14(1):33-63.

Baerg, N. (2020). Crafting Consensus: Why Central Bankers Change their Speech and how Speech Changes the Economy. Oxford University Press, Oxford, UK.

Barnett, M. and Finnemore, M. (1999). The politics, power, and pathologies of international organizations. International Organization, 53(4):699-732.

Barnett, M. and Finnemore, M. (2004). Rules for the World: International Organizations in Global Politics. Cornell University Press.

Baturo, A., Dasandi, N., and Mikhaylov, S. (2017). The united nations general debate. Research and Politics, 4(2):1-9.

Baturo, A. and Mikhaylov, S. (2013). Life of brian revisited: Assessing informational and non-informational leadership tools. Political Science Research and Method, 1(1):139-57.

Bauer, M., Knill, C., and Eckhard, S. (2017). International Bureaucracy: Challenges and Lessons for Public Administration Research. Basingstoke; New York: Palgrave Macmillan. 
Bayram, A. B. and Ta, V. P. (2019). Diplomatic chameleons. Negotiation and Conflict Management Research, 12(1):23-40.

Bearce, D. H. and Bondanella, S. (2007). Intergovernmental organizations, socialization, and member-state interest convergence. International Organization, 61(4):703-733.

Benoit, K., Watanabe, K., Nulty, P., Obeng, A., Wang, H., Lauderdale, B., and Lowe, W. (2013). quanteda: Quantitative analysis of textual data. http://quanteda.io. R package version $0.9 .9-51$.

Berridge, G. R. and James, A. (2003). A Dictionary of Diplomacy, Second Edition. Basingstoke: Palgrave Macmillan.

Bueger, C. and Gadinger, F. (2015). The play of international practice. International Studies Quarterly, 59(3):449-460.

Busch, P.-O., Heinzel, M., Kempken, M., and Liese, A. (2021). Under whose influence? the comparative impact of international bureaucracies on national administrations. Manuscript in proposed IRAS special issue, 1(1):1-1.

Carpenter, D. P. (2001). The Forging of Bureaucratic Autonomy. Princeton University Press, Princeton, NJ.

Dewan, T. and Myatt, D. P. (2008). The qualities of leadership: Direction, communication, and obfuscation. American Political Science Review, 102(3):351-368.

Eckhard, S. and Jorn, E. (2016). International bureaucracies and their influence on policymaking: A review of empirical evidence. Journal of European Public Policy, 23(7):960-78.

Eckhard, S. and Steinebach, Y. (2021). A matter of merit or nationality? staff recruitment and geographical representation in ios. Manuscript in proposed IRAS special issue, 1(1):1-1.

Fang, I. (1966). The "easy listening formula". Journal of Broadcasting and Electronic Media, 11(1):63-68. 
Finnemore, M. (1996). National Interests in International Society. Cornell University Press, Ithaca, NY.

Finnemore, M. and Sikkink, K. (2001). Taking stock: The constructivist research program in international relations and comparative politics. Annual Review of Political Science, 4:391416.

Flesch, R. (1948). A new readability yardstick. Journal of Applied Psychology, 32(3):221-33.

Gertz, G. (2018). Commercial diplomacy and the informal settlement of investment disputes. International Studies Quarterly, 62(1):94-107.

Halliday, T., Pacewicz, J., and Block-Lieb, S. (2013). Who governs? delegations and delegates in global trade lawmaking. Regulation and Governance, 7:279-298.

Hawkins, D., Lake, D., Nielson, D., and Tierney, M. (2006). Delegation under anarchy: States, international organizations and principal-agent theory. In Hawkins, D., Lake, D., Nielson, D., and Tierney, M., editors, Delegation and Agency in International Organizations, pages 3-38. Cambridge University Press, New York.

Jacobson, H. K. (1967). Deriving data from delegates to international assemblies: A research note. International Organization, 21(3):592-613.

Johnson, T. (2013). Institutional design and bureaucrats' impact on political control. Journal of Politics, 75(1):183-197.

Johnson, T. (2014). Organizational Progeny: Why Governments are Losing Control Over the Proliferating Structures of Global Governance. Oxford University Press, Oxford, UK.

Johnston, A. I. (2001). Treating international institutions as social environments. International Studies Quarterly, 45(4):487-515.

Jönsson, C. and Hall, M. (2003). Communication: An essential aspect of diplomacy. International Studies Perspectives, 4(2):195-210. 
Jordan, A. and Tuman, J. P. (2018). Explaining expulsions of u.s. diplomatic personnel from latin america, 1991-2016. Latin American Public, 9(2):238-257.

Kaya, A. and Schofield, L. S. (2020). Which countries send more delegates to climate change conferences? analysis of unfccc cops, 1995-2015. Foreign Policy Analysis, 16(3):478-491.

Keens-Soper, M. (1984). The general assembly reconsidered. In Jennings, A. and Berridge, G., editors, Diplomacy at the United Nations, pages 75-93. Palgrave Macmillan.

Keohane, R. O. (1969). Institutionalization in the united nations general assembly. International Organization, 23(4):859-896.

Kindleberger, C. (1955). Economists in international organizations. International Organization, 9(3):339-350.

Lebovic, J. and Saunders, E. (2016). The diplomatic core: The determinants of high-level us diplomatic visits, 1946-2010. International Studies Quarterly, 60(1):107-23.

Lenz, T., Burilkov, A., and Viola, L. A. (2019). Legitimacy and the cognitive sources of international institutional change: The case of regional parliamentarization. International Studies Quarterly, 63(4):1094-1107.

Lindsey, D. (2017). Diplomacy through agents. International Studies Quarterly, 61(3):544556.

Magnette, P. and Nicolaidis, K. (2004). The european convention: Bargaining in the shadow of rhetoric. West European Politics, 27(3):381-404.

Neumann, I. B. (2012). At Home with the Diplomats: Inside a European Foreign Ministry. Cornell University Press, Ithaca, NY.

Parizek, M. (2017). Control, soft information, and the politics of international organizations staffing. The Review of International Organizations, 12(4):559-583.

Patz, R. and Thorvaldsdottir, S. (2021). Affective language in io bureaucracy reporting: Explaining sentiment shifts in annual reporting of unhcr, unrwa and iom. Manuscript in proposed IRAS special issue, 1(1):1-1. 
Patz, R., Thorvaldsdottir, S., and Goetz, K. (2020). Why do international bureaucrats increase affective language use? a dictionary-based analysis of sentiment in unrwa annual reports. LMU Munich mimeo.

Pedersen, R. F. (1961). National representation in the united nations. International Organization, 15(2):256-266.

Peters, B. G. (1978). Politics of Bureaucracy: A Comparative Perspective. Longman, London.

Peterson, M. J. (2006). The UN General Assembly. London: Routledge.

Pollack, M. A. (1996). Delegation, agency, and agenda setting in the european community. International Organization, 51(1):99-134.

Potter, P. B. (1931). Permanent delegations to the league of nations. The American Political Science Review, 25(1):21-44.

Pouliot, V. (2015). The practice of permanent representation at international organizations. In Sending, O., Pouliot, V., and Neumann, I., editors, Diplomacy and the Making of World Politics, pages 95-100. Cambridge University Press, New York.

Pouliot, V. (2016). International Pecking Orders: The Politics and Practice of Multilateral Diplomacy. Cambridge University Press, New York.

Proksch, S.-O. and Slapin, J. B. (2012). Institutional foundations of legislative speech. American Journal of Political Science, 56(3):520-537.

Ranshofen-Wertheimer, E. F. (1945). The position of the executive and administrative heads of the united nations international organizations. American Journal of International Law, 39(2):323-330.

Schneider, B. R. (1993). The career connection: A comparative analysis of bureaucratic preferences and insulation. Comparative Politics, 25(3):331-350.

Skovgaard Poulsen, L. and Aisbett, E. (2016). Diplomats want treaties: Diplomatic agendas and perks in the investment regime. Journal of International Dispute Settlement, 7(6):72-91. 
Smith, A. (1996). Diversionary foreign policy in democratic systems. International Studies Quarterly, 40(1):133-153.

Tallberg, J. (2002). Delegation to supranational institutions: Why, how, and with what consequences? West European Politics, 25(1):23-46.

Thompson, K. W. (1965). The new diplomacy and the quest for peace. International Organization, 19(3):394-409.

Vaubel, R., Dreher, A., and Soylu, U. (2007). Staff growth in international organizations. Public Choice, 133:275-295.

Wagner, N., Ege, J., and Bauer, M. (2021). How do international bureaucrats affect policy outputs? explaining ipa influence strategies in international organizations. Manuscript in proposed IRAS special issue, 1(1):1-1.

Webster, C. K. (1947). The making of the charter of the united nations. History, 32(115):16-38.

Wendt, A. (1987). The agent-structure problem in international relations theory. International Organization, 41:34-50.

Wertheim, S. (2012). The league of nations: a retreat from international law? Journal of Global History, 7:210-232.

Wiseman, G. (2015). Diplomatic practices at the united nations. Cooperation and Conflict, $50(3): 316-333$.

Young, L. and Soroka, S. (2012). Affective news: The automated coding of sentiment in political texts. Political Communication, 29(2):205-31. 